\title{
Bactericidal activity of human serum against strains of Klebsiella from different sources
}

\author{
G. R. BENGE*
}

Public Health Laboratory and Department of Microbiology, Central Middlesex Hospital, Acton Lane, London NW10 7NS

\begin{abstract}
Summary. One hundred and eighty strains of Klebsiella were tested for sensitivity to pooled normal human serum, capsular type and faecal coliform reaction. Strains of $K$. pneumoniae isolated from clinical infections were more likely to be serum resistant than those from the gut flora or environmental sources. For $K$. oxytoca strains, there was no significant correlation between serum sensitivity and source of isolation. Of 60 strains of $K$. oxytoca tested, $19(32 \%)$ were serum resistant, as were $27(23 \%)$ of 120 strains of $K$. pneumoniae. Strains of $K$. pneumoniae from human sources gave positive reactions in the faecal coliform test more frequently than strains from environmental sources. There was no correlation between a positive faecal coliform reaction and resistance to the bactericidal effect of human serum. Strains of capsular type K21 were isolated more frequently from clinical infections and were more often serum resistant than other strains. Serum resistance appears to be a virulence factor in strains of $K$. pneumoniae but does not account for the difference in pathogenicity between $K$. pneumoniae and $K$. oxytoca.
\end{abstract}

\section{Introduction}

Gram-negative bacilli are important causes of morbidity and mortality in hospital patients (Wolff and Bennett, 1974). Members of the genus Klebsiella are a prominent cause of nosocomial infections (CDC National Nosocomial Infection Study Report, 1977) including bacteraemia (Young, 1982), and in these patients may be a leading cause of mortality (Young et al., 1982). Strains may also cause widespread outbreaks, particularly when antibiotic multi-resistant (Price and Sleigh, 1970; Hill et al., 1974; Curie et al., 1978). The immediate source of infection has usually been assumed to be the endogenous bowel flora (Montgomerie et al., 1970; Selden et al., 1971), although the rate of acquisition and length of carriage have not been fully established. Klebsiellae are also widely distributed in the natural environment including surface waters (Matsen et al., 1974; Knittel, 1975) and vegetables (Brown and Seidler, 1973). The role of environmental strains in human infection has not been clarified, although it has been shown that strains found in hospital food can colonise the gut (Cooke et al., 1980).

Within the genus Klebsiella, both $K$. oxytoca and $K$. pneumoniae are commonly isolated from the

Received 18 Aug. 1987; revised version accepted 17 Dec. 1987. *Present address: Department of Microbiology, Northwick Park Hospital, Harrow HA1 3UJ. environment (Duncan and Razzell, 1972) and from faeces (Davis and Matsen, 1974). However, $K$. oxytoca strains constitute only $6 \%$ of clinical isolates (Edwards and Ewing, 1972). One property that has been suggested to be important in the ability of bacteria to cause infection is resistance to the bactericidal effect of human serum (Vosti and Randall, 1970; Gower et al., 1972; McCabe et al., 1978). The faecal coliform reaction has previously been shown to be more frequently positive with clinical than with environmental strains (Bagley and Seidler, 1977). Certain capsular types are more commonly isolated from hospital patients. It has been suggested that such capsular types possess an epidemiological advantage over other strains allowing them to colonise and infect hospital patients (Casewell and Talsania, 1979; Riser and Noone, 1981).

In the present study, Klebsiella strains from different sources were examined for sensitivity to human serum. Serum sensitivity was also examined in relation to the faecal coliform reaction and the capsular serotype of strains.

\section{Materials and methods}

\section{Bacterial strains}

One hundred and eighty strains were studied. Presumptive identification was made with Donovan's medium 
(Donovan, 1966), together with a positive urease test and a negative ornithine decarboxylase reaction. Full identification and speciation was by standard methods (Cowan and Steel, 1974). Strains were identified as K. pneumoniae (senso lato) or $K$. oxytoca by the indole reaction. All strains were selected from sources distinct in time and location and were allotted to one of three groups: (i) strains from patients with various infections, principally septicaemia and pneumonia, in which the strains were believed to be clinically significant; (ii) strains isolated from the faeces of healthy food handlers; (iii) strains isolated from various environmental sources. Each group contained 40 strains of $K$. pneumoniae and twenty strains of $K$. oxytoca.

\section{Serum}

Normal human serum was obtained by pooling the sera from a number of healthy adults who were not receiving antibiotics; it was stored in small volumes at $-70^{\circ} \mathrm{C}$. This pooled serum (PNHS) was tested for the absence of anti-bacterial activity by agar diffusion with Staphylococcus aureus NCTC 6571 and Escherichia coli NCTC 10418 control strains. Because the classical complement pathway has been shown to be important in the serum killing of Escherichia coli (Roberts and Phillips, 1983), the presence of somatic antibody to enterobacteria was tested in an indirect immunofluorescence test with E. coli and fluorescein labelled anti-human immunoglobulin (Borroughs Wellcome Ltd).

\section{Serum bactericidal assay}

Test strains were grown overnight in Nutrient Broth (Oxoid) and were diluted to $10^{4} \mathrm{cfu} / \mathrm{ml}$ in $5 \mathrm{ml}$ of fresh nutrient broth. The diluted suspensions were incubated at $37^{\circ} \mathrm{C}$ for $2 \mathrm{~h}$ to give a $\log$-phase culture of $c .10^{5} \mathrm{cfu} / \mathrm{ml}$. The cultures were centrifuged ( $1500 \mathrm{~g}$ for $5 \mathrm{~min}$ ) and the deposit resuspended in $5 \mathrm{ml}$ of phosphate buffered saline. Equal volumes $(0.2 \mathrm{ml})$ of this suspension and PNHS were mixed before incubation in a $37^{\circ} \mathrm{C}$ water bath. At $0,60,120$, and $180 \mathrm{~min}$ viable counts were made on Nutrient Agar (Oxoid). All tests were done in duplicate.
Strains were termed serum sensitive if the viable count dropped to $<1 \%$ of the initial value and serum resistant if $>90 \%$ of organisms survived after $180 \mathrm{~min}$. Strains that gave results between these values were of intermediate sensitivity.

\section{Capsular typing}

Capsular typing was done by the Klebsiella Reference Laboratory, Public Health Laboratory, Coventry, with antisera to 72 types. Typing was by counter immunoelectrophoresis (Palfreyman, 1978). Strains that gave negative results by this method were further tested for a positive Quellung reaction.

\section{Faecal coliform reaction}

Strains were inoculated into Formate Lactose Glutamate Broth (Oxoid) which was incubated in a waterbath at $44^{\circ} \mathrm{C}$. A positive reaction was the production of acid and gas after overnight incubation.

\section{Statistical analyses}

The level of probability was determined by a $\mathrm{X}^{2}$ test with Yates's correction.

\section{Results}

The serum sensitivity of strains of $K$. pneumoniae and $K$. oxytoca is shown in table I. Of the strains tested $119(66 \%)$ were serum sensitive and $46(26 \%)$ were serum resistant. More strains from clinical infections were serum resistant than were strains from either of the other sources. The difference in sensitivity to PNHS between strains causing clinical infection (26) and strains isolated from the environment $(6)$ was statistically significant $(\mathrm{p}<$ $0 \cdot 01$ ).

A greater proportion of strains of $K$. oxytoca $(32 \%)$ were serum resistant than were strains of $K$.

Table I. The sensitivity to PNHS of strains of $K$.pneumoniae and $K$. oxytoca from different sources

\begin{tabular}{|c|c|c|c|c|c|c|}
\hline \multirow[b]{3}{*}{ Source of strain } & \multicolumn{6}{|c|}{ Number (\%) of strains with given response } \\
\hline & \multicolumn{3}{|c|}{ K. pneumoniae } & \multicolumn{3}{|c|}{ K. oxytoca } \\
\hline & $\mathbf{S}$ & I & $\mathbf{R}$ & S & I & $\mathbf{R}$ \\
\hline Clinical infections & $21(53)$ & $3(7)$ & $16(40)$ & $11(55)$ & $2(10)$ & $7(35)$ \\
\hline Faecal carriage & $28(70)$ & $3(7)$ & $9(23)$ & $11(55)$ & $1(5)$ & $8(40)$ \\
\hline Environment & $33(83)$ & $5(12)$ & $2(5)$ & $15(75)$ & $1(5)$ & $4(20)$ \\
\hline Total & $82(68)$ & $11(9)$ & $27(23)$ & $37(62)$ & $4(7)$ & $19(32)$ \\
\hline
\end{tabular}

$\mathrm{S}=$ serum sensitive, $\mathrm{I}=$ intermediate, $\mathrm{R}=$ resistant. 
pneumoniae $(23 \%)$ although this difference was not statistically significant $(0 \cdot 1>p>0 \cdot 05)$. A higher proportion of strains of both species were serum resistant amongst those from clinical sources than amongst those from the environment but this difference was significant only for strains of $K$. pneumoniae $(\mathrm{p}<0.01)$. There was also a marked but not statistically significant difference in serum sensitivity between strains of $K$. pneumoniae from clinical infection and those from the normal gut flora $-40 \%$ of clinical strains were resistant and $23 \%$ of faecal strains. In contrast there was no difference in serum sensitivity between strains of $K$. oxytoca isolated from human sources.

Capsular typing of the 180 strains identified a total of 57 capsular types: 27 types were represented by one strain only, 13 by two strains, 4 by four strains and 8 by five or more strains; 22 strains were non-typable. The most common serotype was type 21 (24 strains, 13\%), type 2 (12 strains, $7 \%$ ) being next most common. There was no association between capsular type and species. The source distribution of the six most common types and nontypable strains is shown in table II. Strains of serotype $\mathrm{K} 21$ were more likely to be isolated from a clinical source than from other sources, although this was not statistically significant $(0 \cdot 1>p>0 \cdot 05)$. There was no significant association between any other serotype and source. The sensitivity to PNHS of the most common serotypes is shown in table III. When adjusted to reflect the source of isolate, type K21 was significantly more likely to be serum resistant than the strains generally $(\mathrm{p}<0.02)$. There was no correlation between serum sensitivity and capsular type for other serotypes.

Of the 60 strains of $K$. oxytoca tested, four (7\%) gave a positive faecal coliform reaction. These strains were not confined to any specimen group. A much higher proportion of $K$. pneumoniae strains

Table II. Source of isolation of capsular types found in more than five strains

\begin{tabular}{c|cccc}
\hline & \multicolumn{4}{|c}{ Number of strains } \\
$\begin{array}{c}\text { Capsular } \\
\text { type }\end{array}$ & Clinical & Faecal & Environmental & Total \\
\cline { 2 - 5 } & 13 & 7 & 4 & 24 \\
21 & 6 & 3 & 3 & 12 \\
2 & 4 & 3 & 1 & 8 \\
30 & 1 & 3 & 3 & 7 \\
53 & 1 & 2 & 3 & 6 \\
18 & 3 & 1 & 2 & 6 \\
68 & 5 & 7 & 10 & 22 \\
non-typable & & & & \\
\hline
\end{tabular}

Table III. Serum sensitivity of capsular types found in more than five strains

\begin{tabular}{c|rrrr}
\hline & \multicolumn{4}{|c}{ Number of strains } \\
\cline { 2 - 4 } Capsular type & S & I & R & Total \\
\hline 21 & 4 & 7 & 13 & 24 \\
2 & 6 & 1 & 5 & 12 \\
30 & 4 & 1 & 3 & 8 \\
53 & 7 & 0 & 0 & 7 \\
18 & 4 & 1 & 1 & 6 \\
68 & 2 & 0 & 4 & 6 \\
non-typable & 14 & 2 & 6 & 22 \\
\hline
\end{tabular}

$\mathrm{S}=$ serum sensitive, $\mathrm{I}=$ intermediate, $\mathrm{R}=$ resistant.

$(61 \%)$ gave a positive reaction (table IV). Strains from human sources were significantly more likely to be faecal coliform positive than environmental strains $(\mathrm{p}<0.02)$; there was no difference between strains isolated from the gut and those from clinical sources (29 and 28 strains positive respectively). There was no correlation between a positive faecal coliform reaction and resistance to the bactericidal activity of PNHS in strains of $K$. pneumoniae (table V).

Table IV. Faecal coliform reaction of strains of $K$. pneumoniae from different sources

\begin{tabular}{l|cc}
\hline & \multicolumn{2}{|c}{ Number $(\%)$ of strains } \\
\cline { 2 - 3 } Source of strain & FC positive & FC negative \\
\hline Clinical infections & $28(70)$ & $12(30)$ \\
Faecal carriage & $29(73)$ & $11(27)$ \\
Environment & $16(40)$ & $24(60)$ \\
Total & $73(61)$ & $47(39)$ \\
\hline
\end{tabular}

Table V. Relationship between faecal coliform reaction and sensitivity to PNHS of strains of $K$. pneumoniae

\begin{tabular}{l|ccc}
\hline & \multicolumn{2}{|c}{ Number $(\%)$ of strains } \\
\cline { 2 - 3 } $\begin{array}{l}\text { Response } \\
\text { to PNHS }\end{array}$ & FC positive & FC negative & Total \\
\hline Sensitive & $52(63)$ & $30(37)$ & 82 \\
Intermediate & $7(64)$ & $4(36)$ & 11 \\
Resistant & $14(52)$ & $13(48)$ & 27 \\
Total & 73 & 47 & 120 \\
\hline
\end{tabular}




\section{Discussion}

The properties of Klebsiella spp. that determine virulence are poorly understood. It is well recognised that normal human serum possesses bactericidal activity against a wide range of gram-negative bacteria. It has been suggested that resistance to this bactericidal activity may be a significant virulence factor. Strains of $E$. coli isolated from cases of bacteraemia are more often serum resistant than are gut strains (Vosti and Randall, 1970; McCabe et al., 1978). Serum resistance has also been associated with virulence in several other organisms, including Serratia marcescens (Simberkoff et al., 1976), Pseudomonas aeruginosa (Borowski and Schiller, 1983), Neisseria gonorrhoeae (Schoolnik et al., 1976; Eisenstein et al., 1977), and Vibrio vulnificus (Johnson et al., 1984). In this study, strains of $K$. oxytoca were resistant to the bactericidal activity of PNHS more frequently than strains of $K$. pneumoniae. The difference in pathogenicity of the two species is, therefore, not due to the ability to grow in normal human serum. Strains of $K$. pneumoniae causing clinical infection were more likely to be serum resistant than strains from other sources, whereas there was no significant difference between strains of $K$. oxytoca from different sources. The virulence of strains of $K$. pneumoniae is likely to be increased by the ability to grow in the presence of bactericidal serum components and serum resistance may represent an important virulence factor in these strains. Strains of $K$. pneumoniae from the gut flora were more frequently serum resistant than environmental strains but were less often serum resistant than strains from clinical

\section{REFERENCES}

Bagley S T, Seidler R J 1977 Significance of faecal coliformpositive Klebsiella. Applied and Environmental Microbiology 33: 1141-1148.

Borowski R S, Schiller N L 1983 Examination of the bactericidal and opsonic activity of normal human serum for a mucoid and non-mucoid strain of Pseudomonas aeruginosa. Current Microbiology 9: 25-30.

Brown C, Seidler R J 1973 Potential pathogens in the environment: Klebsiella pneumoniae, a taxonomic and ecological enigma. Applied Microbiology 25: 900-904.

Casewell M, Talsania H G 1979 Predominance of certain Klebsiella capsular types in hospitals in the United Kingdom. Journal of Infection 1 : 77-79.

Centers for Disease Control 1979. National nosocomial infections. Study report, annual summary 1977 . US Department of Health and Human Sciences, Washington, DC

Cooke E M, Sazegar T, Edmondson A S, Brayson J C, Hall D 1980 Klebsiella species in hospital food and kitchens: a source of organisms in the bowel of patients. Journal of Hygiene 84: 97-101. infections. It is probable that infecting strains originate from the gut flora but such isolates represent only a small proportion of the faecal strains.

The most common capsular types found in this study were types $\mathrm{K} 21$ and $\mathrm{K} 2$. The predominance of these types among clinical isolates has been reported previously (Casewell and Talsania, 1979). In the present study, type K21 was isolated significantly more frequently from clinical infections than would have been expected in a normal distribution. No significant correlation was found between other serotypes and the site of isolation. Type K21 strains were also significantly more likely to be serum resistant than other strains.

The results from this study confirm that for strains of $K$. pneumoniae the faecal coliform reaction is useful in differentiating between those from human and environmental sources. The results of the faecal coliform tests with faecal strains were similar to those of Edmondson et al. (1980) but differed from those of Pease et al. (1982) who found only two of 22 faecal strains of $K$. pneumoniae to be positive. This test does not help in distinguishing strains of $K$. pneumoniae from different human sources or the source of strains of $K$. oxytoca.

Resistance to the bactericidal effect of human serum is useful in determining the clinical significance of strains of $K$. pneumoniae. The ability to grow in the presence of human serum may also explain the increased ability of type K21 strains to cause infection. However differences in serum resistance do not explain the greater pathogenicity of $K$. pneumoniae compared with $K$. oxytoca.

Cowan S T (ed) 1974 Cowan and Steel's Manual for the identification of medical bacteria, 2nd edn, Cambridge University Press.

Curie K, Speller D C E, Simpson R A, Stephens M, Cooke D I 1978 A hospital epidemic caused by gentamicin resistant Klebsiella aerogenes. Journal of Hygiene 80 : 115-123.

Davis T J, Matsen J M 1974 Prevalence and characteristics of Klebsiella species: relation to association with a hospital environment. Journal of Infectious Diseases 130: 402-405.

Donovan T J 1966 A Klebsiella screening medium. Journal of Medical Laboratory Technology 23: 194-197.

Duncan D W, Razzell W E 1972 Klebsiella biotypes among coliforms isolated from forest environments and farm produce. Applied Microbiology 24: 933-938.

Edmondson A S, Cooke E M, Wilcock A P D, Shinebaum R 1980 A comparison of the properties of Klebsiella strains isolated from different sources. Journal of Medical Microbi$\operatorname{olog} y$ 13: 541-550.

Edwards P R, Ewing W H 1972 Identification of Enterobacteriacae, 3rd edn, Burgess Publishing Company, Minneapolis, p 290.

Eisenstein B I, Lee T J, Sparling P F 1977 Penicillin sensitivity 
and serum resistance are independent attributes of strains of Neisseria gonorrheae causing disseminated gonococcal infection. Infection and Immunity 15 : 834-841.

Gower P E, Taylor P W, Koutsaimanis K G, Roberts A P 1972 Serum bactericidal activity in patients with upper and lower urinary tract infections. Clinical Science 43: 13-22.

Hill H R, Hunt C E, Matsen J M 1974 Nosocomial colonization with Klebsiella type 26 , in a neonatal intensive-care unit associated with an outbreak of sepsis, meningitis, and necrotizing enterocolitis. Journal of Pediatrics 85: 415-419.

Johnson D E, Calia F M, Musher D M, Goree A 1984 Resistance of Vibrio vulnificus to serum bactericidal and opsonizing factors: relation to virulence in suckling mice and humans. Journal of Infectious Diseases 150: 413-418.

Knittel M D 1975 Occurrence of Klebsiella pneumoniae in surface waters. Applied Microbiology 29: 595-597.

Matsen J M, Spindler J A, Blosser R O 1974 Characterization of Klebsiella isolates from natural receiving waters and comparison with human isolates. Applied Microbiology 28: 672-678.

McCabe W R, Kaijser B, Olling S, Uwaydah M, Hanson L A 1978 Escherichia coli in bacteraemia: $\mathrm{K}$ and $\mathrm{O}$ antigens and serum sensitivity of strains from adults and neonates. Journal of Infectious Diseases 138: 33-41.

Montgomerie J Z, Doak P B, Taylor D E M, North J D K, Martin W J 1970 Klebsiella in faecal flora of renal transplant patients. Lancet 2: 787-792.

Palfreyman J M 1978 Klebsiella serotyping by counter-current immunoelectrophoresis. Journal of Hygiene 81 : 219-225.

Pease P E, Tyler R A, England J R, Colthorpe D, Ebringer A 1982 An investigation into the properties of Klebsiella strains from ankylosing spondylitis patients. Journal of Hygiene 89: 119-123.
Price D J E, Sleigh J D 1970 Control of infection due to Klebsiella aerogenes in a neurosurgical unit by withdrawal of all antibiotics. Lancet 2: 1213-1215.

Riser E, Noone P 1981 Klebsiella capsular type versus site of isolation. Journal of Clinical Pathology 34: 552-555.

Roberts A P, Phillips R 1983 The relative importance of the classical and alternative complement pathways in serum bactericidal activity against Escherichia coli. Journal of Medical Microbiology 16: 69-74.

Schoolnik G K, Buchanan T M, Holmes K K 1976 Gonococci causing disseminated gonococcal infection are resistant to the bactericidal effect of normal human sera. Journal of Clinical Investigation 58: 1163-1173.

Selden R, Lee S, Wang W L L, Bennett J V, Eickhoff T C 1971 Nosocomial Klebsiella infections: intestinal colonization as a reservoir. Annals of Internal Medicine 74: 657-664.

Simberkoff M S, Ricupero I, Rahal J J 1976 Host resistance to Serratia marcescens infection: serum bactericidal activity and phagocytosis by normal blood leukocytes. Journal of Laboratory and Clinical Medicine 87 : 206-217.

Vosti K L, Randall E 1970 Sensitivity to serologically classified strains of Escherichia coli of human origin to the serum bactericidal system. American Journal of Medical Sciences 259: 114-119.

Wolff S M, Bennett J V 1974 Gram-negative-rod bacteremia. New England Journal of Medicine 291: 733-734.

Young L S, Stevens P, Kaijser B 1982 Gram-negative pathogens in septicaemic infections. Scandinavian Journal of Infectious Diseases Supplement 31 : 78-94.

Young S E J 1982 Bacteremia 1975-1980: a survey of cases reported to the PHLS Communicable Diseases Surveillance Centre. Journal of Infection 5: 19-26. 